\title{
THE INFLUENCE OF THE SEWING SPEED AND FABRIC THICKNESS ON SEWING MACHINE STITCH FORMATION PARAMETERS
}

Maja Jankoska*, Goran Demboski

(ORIGINAL SCIENTIFIC PAPER)

UDC 687.053:677.011

University "Ss. Cyril and Methodius", Faculty of Technology and Metallurgy,

Department of Textile, Skopje, Macedonia

The paper investigates the effect of the sewing speed and fabric thickness on the sewing thread tension and presser foot displacement. Data collection devices were developed for the acquisition information regarding the thread tension and presser foot displacement during the stitch formation. A software program was created to provide on-line information and data analysis. It was shown that the increase of the fabric thickness and the increase of the sewing speed increase the sewing thread tension. The difference is most expressed at the point of the thread take-up lever highest position in the stitch forming cycle. The increase of the sewing speed and fabric thickness increases the maximum presser foot height. There is a difference in the presser foot displacement shape and timing between the lower and the higher sewing speed.

\section{Introduction}

The apparel industry demands faster changes in setting up machines for new materials and different specifications. The time consumed in this task has been acquiring more and more importance, once it must be done very often, properly and quickly, since the market demands are shorter in quantities and with a higher level of quality required. The introduction of high technologies in the sewing machines is reality that concerns all machine manufacturers. Their main objective is to reduce machine setting times in order to obtain good quality seams.

The first studies on the seam quality were carried out by Dorkin and Chamberlain in 1961 [1]. The relation of the seam pucker occurrence, a common quality problem with the behavior of the feeding system was investigated, and the operation of the feeding system was precisely described. In 1964, Chamberlain and Deery developed a method for measuring the thread tension variation within the stitch formation cycle of a lockstitch machine [2]. The tension signals were analyzed relating the occurring peaks to events in the stitch cycle and the values of the peaks. In his study, Greenberg presented another instrument for the same purpose [3]. In his investigation, Johnson presented a mathematical model for the movement of the presser-foot in a sewing machine, especially concerned on predicting the contact losses between a presser-foot and feed-dogs [4]. A study of sewing dynamics, considering the thread tension and thread consumption as two very important parameters to achieve good quality seams considering different machine set-up (sewing speed, needle, thread pretension) and the material used (fabric and sewing threads), has been presented by Jones [5]. In the meantime, several studies were directed towards the investigation of the behavior of thread tensions and its relations to the seam quality. Jones and Munden describe the geometry and mechanics of the two-thread chainstitch, proposing a method for the measurement of both static and dynamic thread tensions $[6,7]$. Horino et al. [8] and later Kamata et al. [9] carried out the studies on thread tensions in lockstitch sewing machines. They examined the relationship between the needle and bobbin thread tensions, also observing the movement of the check spring, a component that is found in the needle thread path of lockstitch machines. A similar work was carried out by Onoue [10]. Chmielowiec and Lloyd [11] equipped a Pfaff lockstitch machine with the sensors measuring presser-foot force and displacement, thread tension and the needle penetration force. They were able to detect the effect of presser-foot bouncing, and analyzed some correlation between the presser-foot compression force and seam pucker. Alagha et al. [12] discussed the relation between the fabric objective properties and sewing conditions, with the contraction and consumption of sewing threads. The stitch-formation process of a lockstitch sewing machine is investigated with the aid of transducers that facilitate real-time monitoring of the sewing cycle. Kennon and Hayes [13], found that retardation of the fabric-feed timing by up to $25^{\circ}$ results in lowering the stitch forming tension which could have implications for the modification of the seam slippage and the reduction of tension-induced puckering. Carvalho et al. analyzed the effect of pretension on the needle thread tension and thread consumption [14],

\footnotetext{
* Author address: Maja Jankoska, Faculty of Technology and Metallurgy, Rudjer Boskovic 16, 1000 Skopje, Macedonia

E-mail: maja@tmf.ukim.edu.mk

The manuscript received: September, 26, 2017

Paper accepted: November, 30, 2017.
} 
[15]. Kumar et al. [16] analyzed the influence of the tension variation on different types of woven fabrics - light, medium and heavyweight. They found that the increase in the needle thread tension had a significant impact on various types of fabrics probably influenced by the structure and weight of the fabric. A sewing thread type also has a significant impact on the seam performance.

The aim of this paper is to investigate the effect of the sewing speed and fabric structure variations on the sewing thread tension and a presser foot displacement.

\section{Experimental}

\section{Materials}

The sewing thread tension and foot displacement are monitored on a lockstitch sewing machine in order to follow the effect of the machine speed variation and the change of the fabric thickness. The fabrics tested have the same fiber composition (100\% wool), the same warp and weft count and the same weave. The fabrics only differ in weight and thickness (Table 1).

Table 1. Investigated fabric particulars

\begin{tabular}{ccc}
\hline Fabric & $\begin{array}{c}\text { Fabric thickness, } \\
{[\mathbf{m m}]}\end{array}$ & $\begin{array}{c}\text { Fabric weight } \\
{\left[\mathbf{g} / \mathbf{m}^{2}\right]}\end{array}$ \\
\hline A & 0.39 & 213 \\
B & 0.41 & 227 \\
\hline
\end{tabular}

The sewing parameters for the investigation are shown in Table 2.

Table 2. Sewing parameters of the conducted experiment

\begin{tabular}{ccc}
\hline Machine speed & Needle size & Sewing thread \\
\hline $1000 \mathrm{spm}$ & & $100 \%$ PES \\
$3000 \mathrm{spm}$ & $100 \mathrm{Nm}$ & $\mathrm{Tt}=25 \mathrm{tex}$ \\
$4000 \mathrm{spm}$ & & \\
\hline
\end{tabular}

\section{Method}

A lockstitch sewing machine was equipped with several devices in order to acquire, store and analyze the data describing the behavior of the most important parameters involved in the formation of the stitch type 301 , which is the most used stitch in the sewing industry (Figure 1).

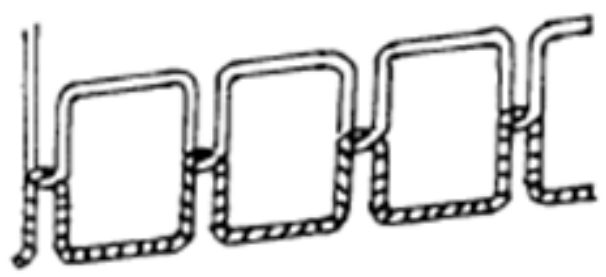

Figure 1. Empirical model of the sewing stitch type 301
The system consists of data collection devices (sensors - cantilever beams strain gauges, encoders, LVDT (Linear Variable Differential Transformer) and hardware for signal conditioning and processing). These devices are connected to a data acquisition board installed in a PC (Figure 2).

There is also a program (developed in LABVIEW), which allows the calibration of the devices, the online graphical display and signal processing functions. The program also includes basic statistical tools, in order to shorten the evaluation of the results.
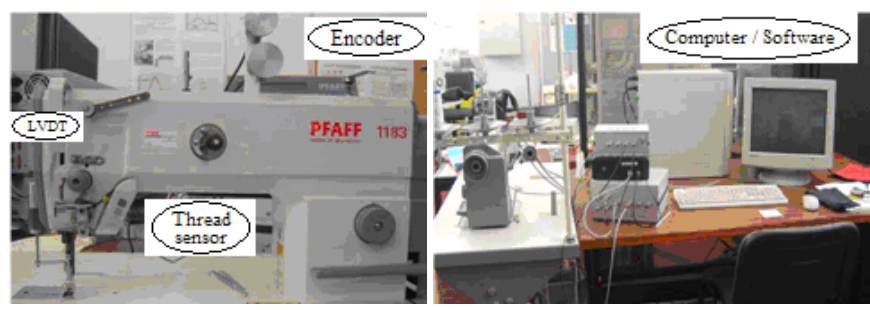

Figure 2. Positioning of control devices in the lockstitch sewing machine and connection to $\mathrm{PC}$

The strain gauge sensor was used to measure the thread tension variation in the needle thread and the thread guider was used to secure the contact between the sensor and the thread during the stitch formation. The sensor is placed between the spring pre-tensioner and the needle in the path of the thread.

The sensor was specifically developed to dynamically measure and track quick variations of the thread tension. This high-sensitivity semiconductor strain gauge sensor has a silicone guider to assure the contact with the thread during the stitch formation and to reduce friction forces.

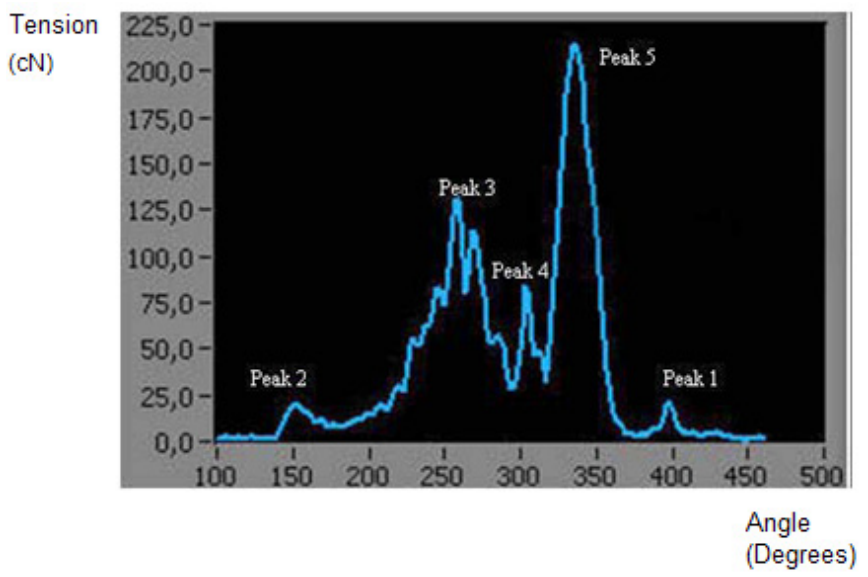

Figure 3. Needle thread tension variation is one complete stitch cycle (average)

\section{Results and discussion}

The effect of the fabric thickness and a sewing speed on the needle thread tension

Figure 3 shows the average tension variation in one 
complete cycle for the needle thread involved in the stitch formation. This graphic is a result of average of 20 stitches acquired in each experiment.

In this study, five characteristic peaks of the thread tension were identified and analyzed in the cycle. Table 3 represents the moment when each peak occurs in the cycle of the formation of the stitch.
In order to evaluate only the influence of the machine speed and material properties on the needle thread tension, other machine set-up parameters were kept constant. Figure 4 represents the effect of the fabric thickness on sewing thread tension for sewing 3000 and $4000 \mathrm{spm}$.

Table 3. Occurrence of five peaks of tension in the thread

\begin{tabular}{|c|c|c|}
\hline Tension Peak & Needle (Degrees) & Occurrence \\
\hline Peak 1 & 40 & Needle contacts the material. \\
\hline Peak 2 & 150 & $\begin{array}{l}\text { Needle reaches its lowest position and starts its movement up. } \\
\text { Thread take-up lever continues its movement down. }\end{array}$ \\
\hline Peak 3 & 260 & $\begin{array}{l}\text { Needle reaches the highest position. Thread take-up lever starts } \\
\text { its movement up. Fabric is being feed by the feed-dog. }\end{array}$ \\
\hline Peak 4 & 305 & $\begin{array}{l}\text { Needle descending from the highest position. Thread take-up } \\
\text { lever continues its movement up pulling the needle thread. Fabric } \\
\text { is being fed by the feed-dog. }\end{array}$ \\
\hline Peak 5 & 335 & $\begin{array}{l}\text { Thread take-up lever reaches a higher position pulling the needle } \\
\text { thread to close the stitch. Needle continues its movement down. }\end{array}$ \\
\hline
\end{tabular}

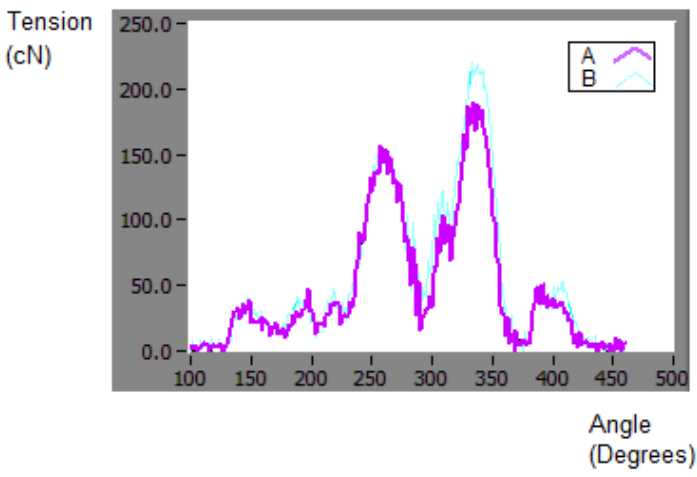

(a)

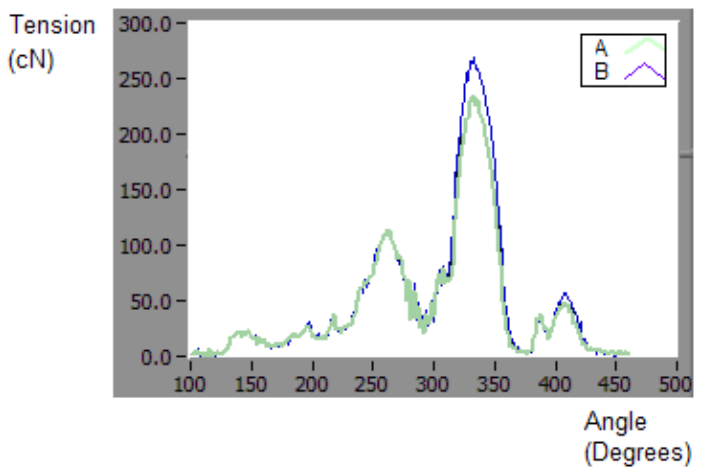

(b)

Figure 4. The sewing thread tension of the lower thickness fabric $(A)$ and the higher thickness fabric (B) at $3000 \mathrm{spm}(\mathrm{a})$ and $4000 \mathrm{spm}$ (b)

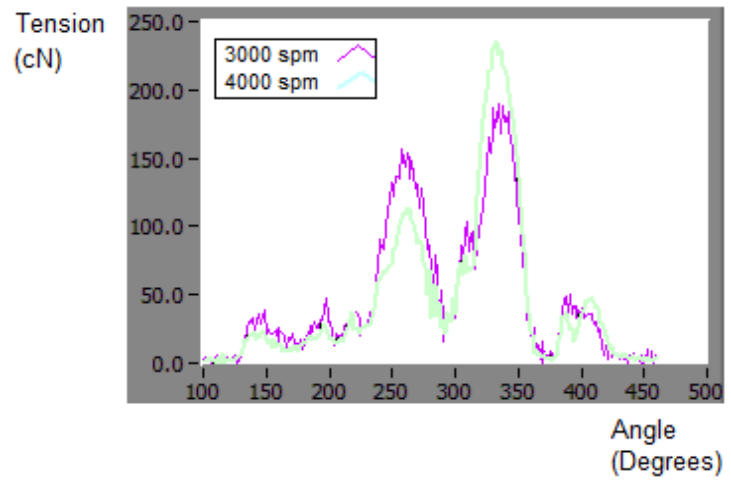

(a)

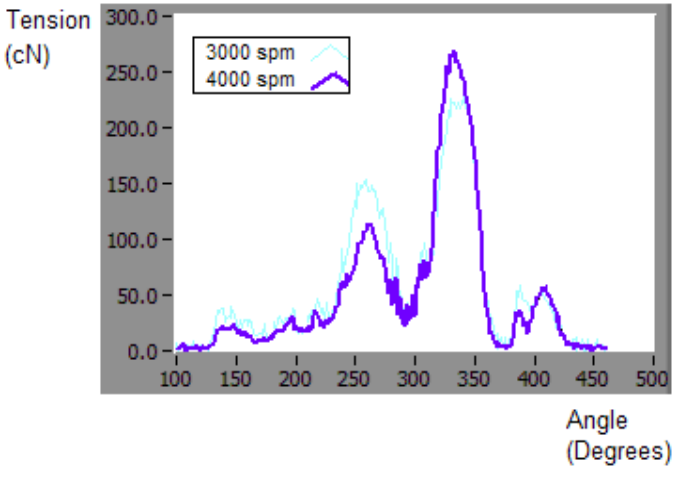

(b)

Figure 5. Sewing thread tension at $3000 \mathrm{spm}$ and $4000 \mathrm{spm}$ sewing speed for fabric $\mathrm{A}$ (a) and fabric B (b)

Figure 4 shows that at both speeds, the thread tension of higher thickness fabrics $(B)$ is higher than of lower thickness fabric $(A)$. The difference is mostly expressed at the highest peak (characteristic tension peak " 5 ") where the thicker sample B obtains the tension of $225 \mathrm{cN}$ and the thinner fabric A tension of $189 \mathrm{cN}$ at the speed of
3000 spm (Figure 4a). The same behavior is confirmed at the sewing speed of $4000 \mathrm{spm}$, where the thicker fabric $(B)$ at the characteristic peak " 5 " obtains the tension of $267.8 \mathrm{cN}$, compared to $236.5 \mathrm{cN}$ of the thinner fabric (A) (Figure 4b). Since at the peak " 5 " the take-up lever tightens the stitch into the material, there is friction between 
the material and the sewing thread. The thicker fabric creates higher friction and consequently increases the thread tension. The difference of the tension created at the peak 5 between fabrics $A$ and $B$ is $27 \mathrm{cN}$ at $3000 \mathrm{spm}$ and $31.3 \mathrm{cN}$ at $4000 \mathrm{spm}$. So, the difference between tensions is higher at the higher machine speed.

Figure 5 shows the thread tension achieved for both fabrics at speeds of $3000 \mathrm{spm} 4000 \mathrm{spm}$. The comparison of the thread tension at various speeds shows a notably higher thread tension registered for both fabrics at $4000 \mathrm{spm}$. This confirms that by increasing the sewing speed, the sewing thread tension increases.
The effect of the fabric thickness and a sewing speed in the presser-foot displacement

At the beginning, in a stitch forming cycle, the feed dog is at the throat plate level at approximately 80 degrees, and then a rising movement follows and the feed dog reaches its maximum position at around 160 degrees. At approximately 260 degrees on its descending movement, it is again at the throat plate level.

During almost half a period of the stitch cycle, fabric feeding occurs and during the other half, the stitch is formed. Therefore, a stitch cycle corresponds to the rotation of 360 degrees of the sewing machine main shaft. The beginning of the cycle ( 0 degrees) is marked when the needle is on its lowest position, after the needle penetration in the fabric.

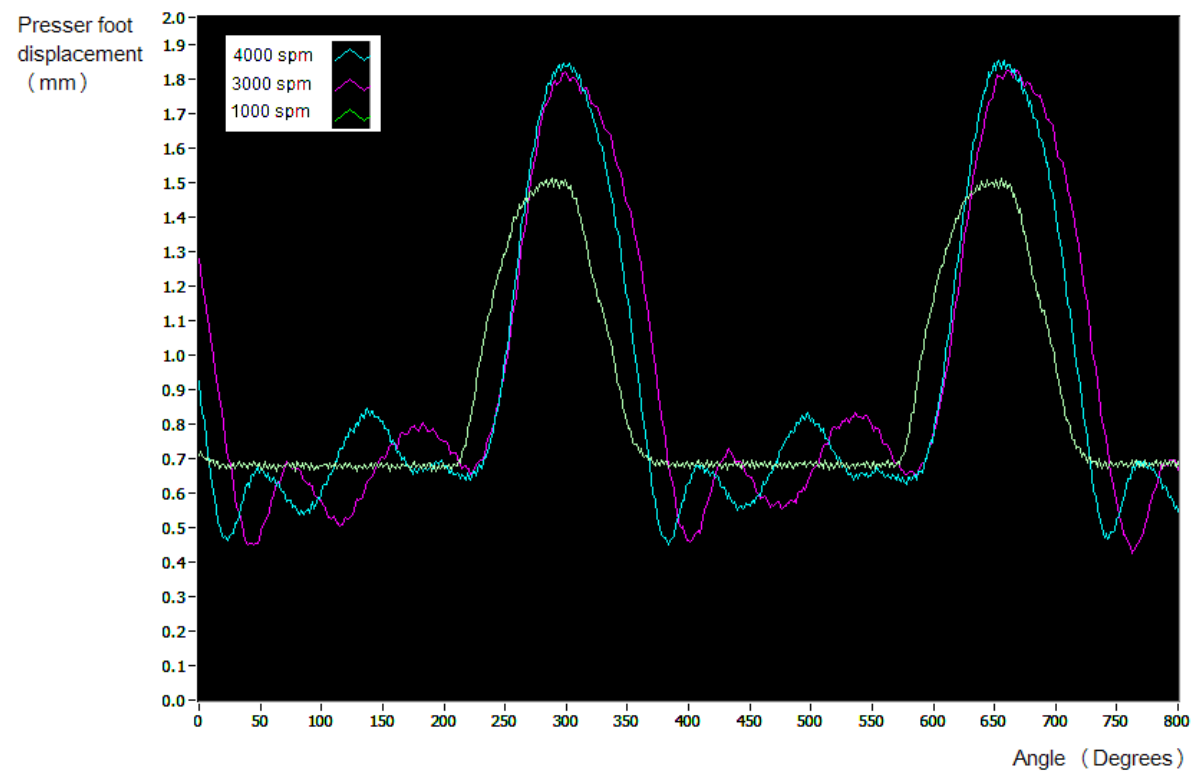

Figure 6. Presser foot displacement waveform at low-speed 1000, medium-speed 3000 and high-speed 4000 spm situation on fabric $A$

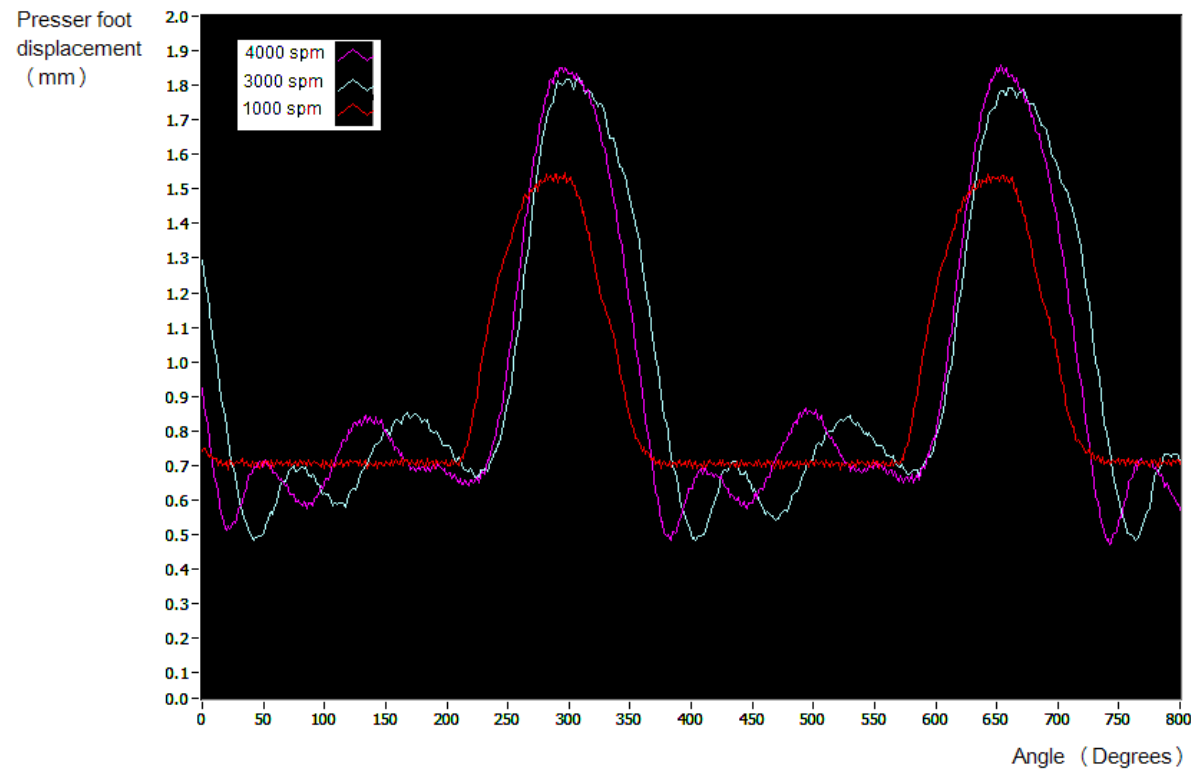

Figure 7. Presser foot displacement waveform at low-speed 1000, medium-speed 3000 and high-speed 4000 spm situation on fabric B 
Table 4 shows maximum heights of the presser foot displacement at the stage of the fabric transportation for seams.

Table 4. Maximum presser foot displacement at the speed of 1000, 3000 and 4000 spm

\begin{tabular}{|c|c|c|c|}
\hline \multirow[t]{3}{*}{ Fabric } & \multicolumn{3}{|c|}{ Max. presser foot displacement $(\mathrm{mm})$} \\
\hline & \multicolumn{3}{|c|}{ Sewing speed } \\
\hline & $1000 \mathrm{spm}$ & $3000 \mathrm{spm}$ & $4000 \mathrm{spm}$ \\
\hline A & 1.510 & 1.815 & 1.879 \\
\hline B & 1.567 & 1.842 & 1.899 \\
\hline
\end{tabular}

Figure 6 and Figure 7 show the presser foot bar displacement obtained for two plies seam for both investigated fabrics at various machine speeds (low speed 1000, medium speed 3000 and high speed 4000).

The graphs show that the presser foot displacement increases with the increase of the sewing speed for both fabrics $A$ and $B$. For the thinner fabric $A$, the maximum height of the displacement at 1000, 3000 and $4000 \mathrm{spm}$ is $1.510,1.815$ and $1.879 \mathrm{~mm}$, respectively. For the thicker fabric $\mathrm{B}$, the maximum height of the displacement at 1000,3000 and $4000 \mathrm{spm}$ is $1.567,1.842$ and 1.899 $\mathrm{mm}$. For all speeds, the maximum height is higher for thicker fabric $\mathrm{B}$. The difference in the presser foot height between 3000 and 4000 spm is much smaller compared to a difference in height from $1000 \mathrm{spm}$ to $3000 \mathrm{spm}$. The maximum foot height for fabric A from 1000 to $3000 \mathrm{spm}$ increases for $20.2 \%$, while from 3000 to $4000 \mathrm{spm}$ it increases for $3.5 \%$. So, the increasing of the speed from $1000 \mathrm{spm}$ to $3000 \mathrm{spm}$ affects a great increase in the presser foot highest position. The picture also shows the difference in the highest presser foot displacement peak for $1000 \mathrm{spm}$ and 3000 and 4000 spm. Namely, at higher speeds of 3000 and $4000 \mathrm{spm}$ this peak is sharper compared to a more blunted peak at the lower speed of $1000 \mathrm{spm}$. Also, the peak at $1000 \mathrm{spm}$ peak has di-fferent timing than at higher sewing speeds. Graphs also show that during the phase of the needle penetration at $1000 \mathrm{spm}$, the presser foot does not oscillates and there are no indices of foot bouncing as it is the case at higher sewing speeds.

\section{Conclusion}

The results of monitoring sewing machine parameters showed that the sewing speed and fabric thickness affect the needle thread tension and the presser foot displacement.

The increase of the fabric thickness increases the sewing thread tension. The difference is most prominent at the sewing thread tension peak at around $335^{\circ}$, when the thread take-up lever reaches its highest position, pulling the needle thread to close the stitch. The sewing thread tension increases with the increase of the sewing speed.
The presser foot displacement increases with the increase of the sewing speed for both investigated fabrics. The maximum presser foot height increases for $20.2 \%$ when the sewing speed rises from 1000 to $3000 \mathrm{spm}$. The presser foot displacement graphs during the stitch forming cycle show differences in the highest peak shape and timing between the lower speed of $1000 \mathrm{spm}$ and the higher speed of 3000 and $4000 \mathrm{spm}$.

Quantitative information on sewing machine parameters during the stitch forming cycle can be of great benefit in monitoring the sewing quality and preventing sewing defects.

\section{References}

[1] M.C. Dorkin, N. H. Chamberlain, Seam Pucker: Its Cause and Prevention, Technological Report $N^{\circ}$. 10, Clothing Institute, 1961.

[2] F.C. Deery, N.H. Chamberlain, A Study of Thread Tension Variations during the Working Cycle in a Lockstitch Sewing Machine, Technological Report N ${ }^{\circ}$. 15, Clothing Institute, 1964.

[3] N.G. Greenberg, (1975). An instrument for measurement of thread dynamic tension characteristics during the sewing operation - Part 2, Clothing Research Journal, 3(2) (1975) 77.

[4] E.M. Johnson, Some Factors Affecting the Performance of High Speed Sewing Machines, Clothing Research Journal, 1(1) (1973) 3-35.

[5] R.J.R. Jones, Reveiw of previous work on the factors affecting the thread dynamic tension characteristics on a lockstitch sewing machinell, Part 1, Clothing Research Journal, 1975.

[6] R.J.R. Jones, D.L. Munden, A Study of the Mechanics and Geometry of the 2-Thread Chainstitch - Part 1 - An Instrument for Measuring Static Needle and Looper Thread Tension, Clothing Research Journal, 8 (1980) 107114.

[7] R.J.R. Jones, D.L. Munden, A Study of the Mechanics and Geometry of the 2-Thread Chainstitch - Part 2 - The Development of an Apparatus for the Measurement of Dynamic Thread Tension, Clothing Research Journal, 9 (1980) 78-83.

[8] T. Horino, Y. Miura, Y. Ando, K. Sakamoto, Simultaneous measurements of needle thread tension and check spring motion of lockstitch sewing machine for industrial use, J. Text. Mach. Soc. Japan, 2 (1982) 30-37.

[9] Y. Kamata, R. Kinoshita, S. Ishikawa, K. Fujisaki, (1984). Disengagement of needle thread from rotating hook, effects of its timing on tightening tension on an industrial single needle lockstitch machine, J. Text. Mach. Soc. Japan, 30(2) (1984) 40-49.

[10] M. Onoue, Influences of the sewing conditions of the lockstitch sewing machine for industrial use on the needle thread tension, J. Soc. Fib. Sci. Tech., Japan, 10 (1984) 395-401.

[11] G.R. Barrett, T.G. Clapp, Coprime Factorization Design of a Novel Maglev Presser Foot Controller, Elsevier Science Ltd, Mechatronics Journal, 5(2/3) (1995) 279-294.

[12] M.J. Alagha, J. Amirbayat, I. Porat I., A Study of Positive Needle Thread Feed During Chainstitch Sewing, Journal of the Textile Institute, 87(2) (1996) 389-395.

[13] W.R. Kennon, S.G. Hayes, The Effects of Feed 
Retardation on Lockstitch Sewing, Journal of the Textile Institute, 91(4) (2000) 509-522.

[14] M.A.F. Carvalho, F.B.N. Ferreira, A.M. Ferreira, The effect of the sewing thread in seam quality and machine setup - Objective evaluation, Proceeding of the International Fiber Conference - Extreme and Aesthetic Textiles, Seoul National University, Seoul, Korea, 2006.

[15] M.A.F. Carvalho, F.B.N. Ferreira, A.M. Ferreira, Study of the Thread Tension and Consumption in a Lockstitch Sewing Machine, Proceedings of 6th World Textile Conference AUTEX, Tampere, Finland, 26-27 de June 2007.
[16] C.S. Sentthil Kumar, K. Ramachandralu, Study on Relationship between Sewing Thread Tension and Fabric, European Journal of Advances in Engineering and Technology, 2(8) (2015) 105-107.

Izvod

\section{UTICAJ BRZINE ŠIVENJA I DEBLJINE TKANINE NA PARAMETRE FORMIRANJA BODA NA ŠIVAĆOJ MAŠINI}

Maja Jankoska, Goran Demboski

Univerzite "Sv. Kiril I Metodije", Tehnološko-metalurški fakultet, Katedra za tekstil, Skopje, Makedonia

$U$ radu se istražuje efekat brzine šivanja i debljine tkanine na zategnutost konca za šivenje i pomeranje papučice. Razvijeni su uređaji za merenje i prikupljanje podataka o zategnutosti konca i pomeranju papučice u fazi formiranja bodova. Izrađen je softver za obezbeđivanje i analizu on-line podataka. Pokazano je da povećanje debljine tkanine i povećanje brzine šivenja povećavaju zategnutost šivaćeg konca. Razlika se najčešće izražava u tački najviše pozicije davača konca u ciklusu formiranja boda. Povećanje brzine šivenja i debljine tkanine povećavaju maksimalnu visinu podizanja papučice. Postoji razlika u obliku krive pomeranja papučice i vremena kod manje i veće brzine šivenja.
(ORIGINALNI NAUČNI RAD)

UDK 687.053:677.011

Ključne reči: monitoring šivaće mašine, zategnutost šivaćeg konca, pomeranje papučice 